\title{
Estimating influenza vaccine effectiveness in Spain using sentinel surveillance data
}

S Jiménez-Jorge (silviajimenezjorge@gmail.com) ${ }^{1,2}$, S de Mateo ${ }^{1,2}, C_{\text {Celgado-Sanz }}^{1,2}$, F Pozo ${ }^{3}$, I Casas ${ }^{3}$, M García-Cenoz $^{2,4}$, J Castilla $^{2,4}$, C Rodriguez ${ }^{5}$, T Vega ${ }^{5}$, C Quiñones ${ }^{6}$, E Martínez ${ }^{6}$, J M Vanrell , J Giménez $^{7}$, D Castrillejo ${ }^{8}$, J M Altzíbar ${ }^{2,9}$, F Carril $^{10}$, J

M Ramos ${ }^{11}$, M C Serrano ${ }^{11}$, A Martínez ${ }^{2,12}$, N Torner ${ }^{2,12}$, E Pérez ${ }^{13}$, V Gallardo ${ }^{13}$, A Larrauri ${ }^{1,2}$, on behalf of the Spanish Influenza Sentinel Surveillance System ${ }^{14}$

1. National Centre of Epidemiology, Institute of Health Carlos III, Madrid, Spain

2. CIBER Epidemiología y Salud Pública (CIBERESP), Institute of Health Carlos III, Madrid, Spain

3. National Centre for Microbiology, National Influenza Reference Laboratory, WHO National Influenza Centre, Institute of Health Carlos III, Madrid, Spain

4. Instituto de Salud Pública de Navarra, Navarre, Spain

5. Dirección General de Salud Pública, Consejería de Sanidad de Castilla y León, Valladolid, Spain

6. Servicio de Epidemiología y Prevención Sanitaria, Dirección General de Salud Pública y Consumo de La Rioja, La Rioja, Spain

7. Servicio de Epidemiología, Dirección General de Salut Pública, Mallorca, Baleares, Spain

8. Servicio de Epidemiología. Dirección General de Sanidad y Consumo, Consejería de Bienestar Social y Sanidad, Ciudad Autónoma de Melilla, Melilla, Spain

9. Dirección de Salud Pública de Gipuzkoa, País Vasco, San Sebastián, Spain

10. Servicio de Salud Pública, Departamento de Salud, Gobierno del País Vasco, Álava, Spain

11. Dirección General de Salud Pública, Servicio Extremeño de Salud, Junta de Extremadura, Mérida, Spain

12. Servicio de Vigilancia Epidemiológica, Dirección General de Salud Pública, Departament de Salut, Generalitat Catalunya, Barcelona, Spain

13. Servicio de Epidemiología y Salud Laboral, Secretaría General de Salud Pública y Participación, Consejería de Salud de Andalucía, Sevilla, Spain

14. Institutions involved in the network are listed at the end of the article (vgripe.isciii.es/gripe/)

Citation style for this article:

Jiménez-Jorge S, de Mateo S, Delgado-Sanz C, Pozo F, Casas I, García-Cenoz M, Castilla J, Rodriguez C, Vega T, Quiñones C, Martínez E, Vanrell JM, Giménez

J, Castrillejo D, Altzíbar JM, Carril F, Ramos JM, Serrano MC, Martínez A, Torner N, Pérez E, Gallardo V, Larrauri A, on behalf of the Spanish Influenza Sentine Surveillance System. Estimating influenza vaccine effectiveness in Spain using sentinel surveillance data. Euro Surveill. 2015;20(28):pii=21187. Available online:

http://www.eurosurveillance.org/ViewArticle.aspx?Articleld=21187

We aimed to estimate influenza vaccine effectiveness (VE) against laboratory-confirmed influenza during three influenza seasons (2010/11 to 2012/2013) in Spain using surveillance data and to compare the results with data obtained by the cycEVA study, the Spanish component of the Influenza Monitoring Vaccine Effectiveness (I-MOVE) network. We used the test-negative case-control design, with data from the Spanish Influenza Sentinel Surveillance System (SISS) or from the cycEVA study. Cases were laboratory-confirmed influenza patients with the predominant influenza virus of each season, and controls were those testing negative for any influenza virus. We calculated the overall and age-specific adjusted VE. Although the number of patients recorded in the SISS was three times higher than that in the cycEVA study, the quality of information for important variables, i.e. vaccination status and laboratory results, was high in both studies. Overall, the SISS and cycEVA influenza VE estimates were largely similar during the study period. For elderly patients (> 59 years), the SISS estimates were slightly lower than those of CycEVA, and estimates for children (0-14 years) were higher using SISS in two of the three seasons studied. Enhancing the SISS by collecting the date of influenza vaccination and reducing the percentage of patients with incomplete information would optimise the system to provide reliable annual influenza VE estimates to guide influenza vaccination policies.

\section{Introduction}

Influenza causes considerable morbidity worldwide, even among those who are not in vulnerable high-risk groups, and therefore represents a public health problem with socio-economic implications [1]. Influenza vaccination has the potential to prevent annual morbidity and premature mortality. The influenza vaccine is reformulated every year and consequently its effectiveness must be estimated annually [1]. In Europe, seasonal and pandemic influenza vaccine effectiveness (VE) has been monitored since the 2008/09 influenza season through the Influenza Monitoring Vaccine Effectiveness (I-MOVE) project [2], a publicly funded network supported by the European Centre for Disease Prevention and Control (ECDC) and European Union (EU) Member States in the framework of the European sentinel influenza systems. Since the inception of I-MOVE, Spain has participated through an observational case-control study to monitor influenza VE in Spain (cycEVA). This study is conducted within the framework of wellestablished sentinel influenza networks comprising the Spanish Influenza Sentinel Surveillance System (SISS). 
Test-negative controls and laboratory-confirmed influenza cases by type/subtype of influenza virus and epidemiological week, Spanish Influenza Sentinel Surveillance System (A) and cycEVA study (B), 2010/11, 2011/12 and 2012/13 seasons, Spain

A. Spanish Influenza Surveillance System
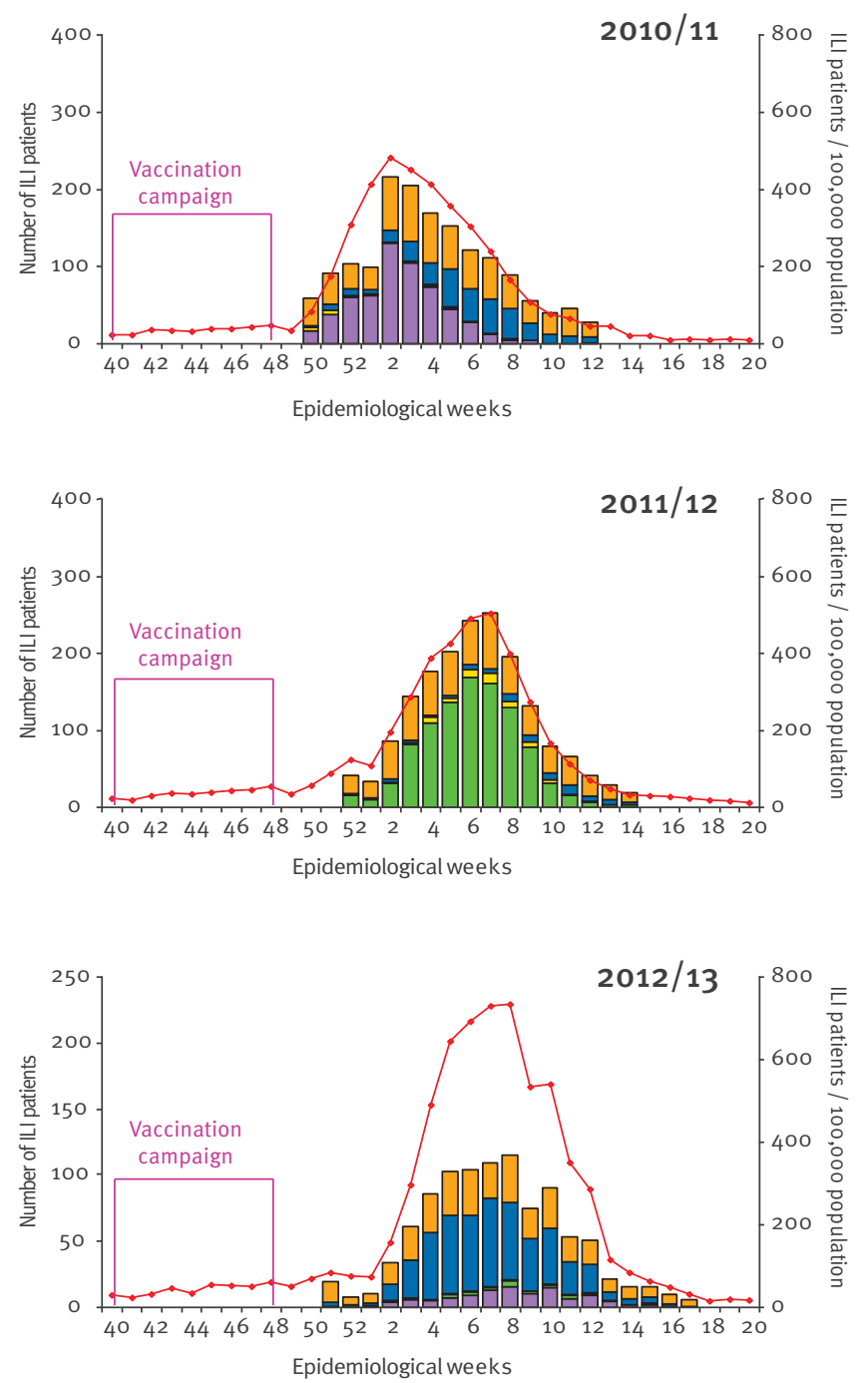

\section{B. cycEVA study}
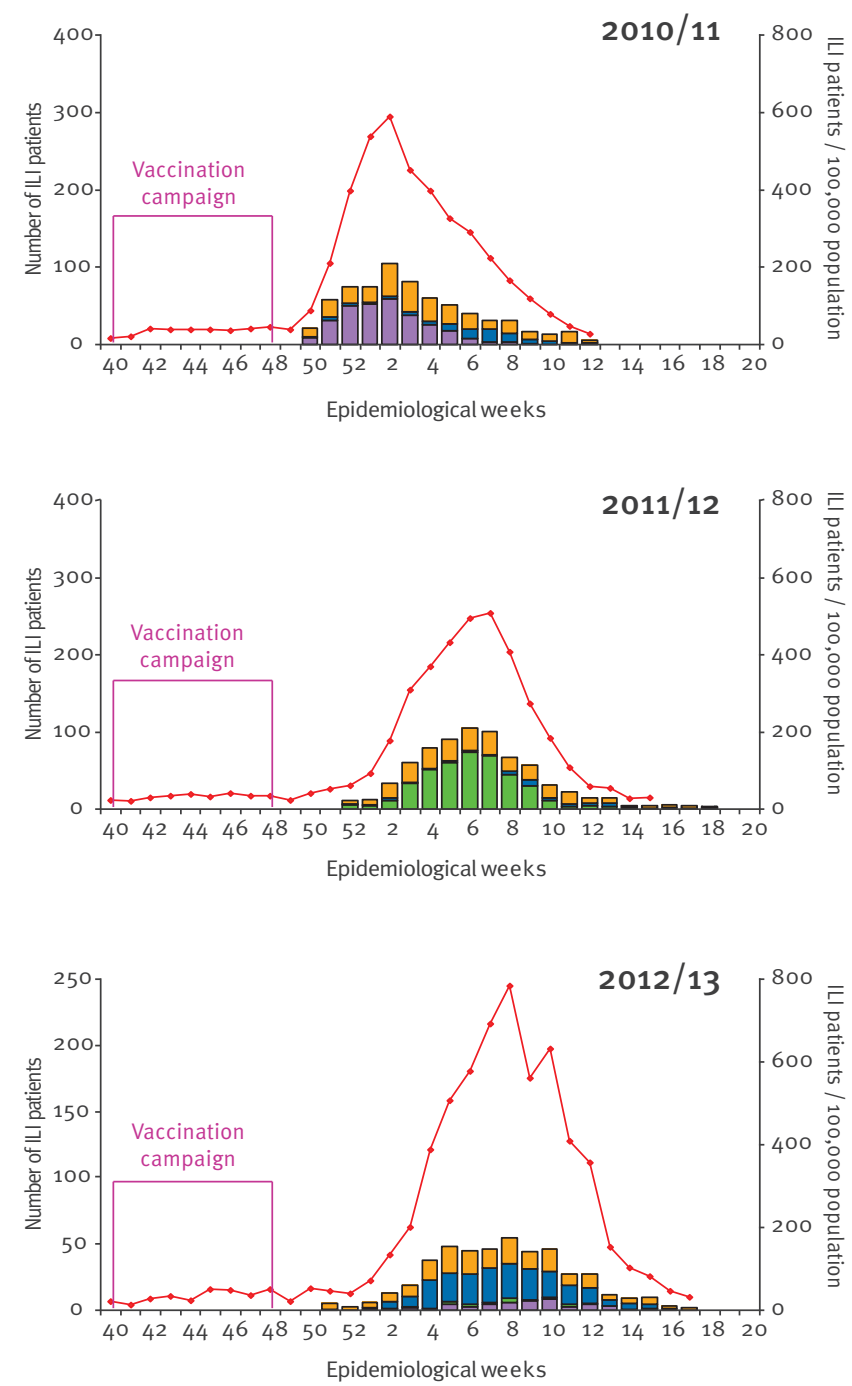

\footnotetext{
$\square$ Test-negative controls

$\sim$ ILI incidence sentinel regions
$\square \quad$ Influenza B-positive cases

$\square$ Influenza A not subtyped-positive cases

$\square$ Influenza $A\left(\mathrm{H}_{3} \mathrm{~N}_{2}\right)$-positive cases

$\square$ Influenza $\mathrm{A}\left(\mathrm{H}_{1} \mathrm{~N}_{1}\right)$ pdmog-positive cases
}

cycEVA study: the Spanish component of the Influenza Monitoring Vaccine Effectiveness (I-MOVE) network; ILI: influenza-like illness.

Participating sentinel physicians follow a European protocol specifically designed for this study [3]. The protocol includes systematic swabbing of recruited patients and recording the date of influenza vaccination and information on potential confounding factors that have not been historically collected during influenza surveillance. Through five influenza seasons, the cycEVA study has provided timely and reliable [4-8] influenza VE estimates and has been useful in guiding public vaccination policy at the national and European level [9]. However, after the initial ECDC funding was exhausted (December 2012), the Spanish cycEVA study encountered serious difficulties in continuing to measure influenza VE. Therefore, a major challenge in Spain and the rest of Europe is sustaining these VE studies.

Influenza surveillance data have been used in Australia, the United Kingdom (UK) and Canada [10-12] to monitor influenza VE using the test-negative control approach, an efficient method of estimating VE [13]. Because 
surveillance data are already available, this method is less costly than observational studies.

The SISS was established in 1996 to provide timely epidemiological and virological information on influenza activity in Spain [14]. The SISS also participates in the European Influenza Surveillance Network (EISN). After more than 15 years, the SISS has been demonstrated to be a robust system for monitoring seasonal influenza [15]. Since the 2009/10 pandemic season, the SISS has been enhanced by increasing the number of swabs taken for virological confirmation, adopting a systematic sampling procedure and collecting information on the presence of chronic conditions and risk factors [16]. These approaches have positively affected the SISS by improving the quality and accuracy of its surveillance information and, consequently, enabling it to provide estimates of influenza VE [17]. In the present study, we aimed to estimate influenza VE against laboratory-confirmed influenza using surveillance data from the SISS during the three influenza seasons (2010/11 to 2012/13) following the $\mathrm{A}\left(\mathrm{H}_{1} \mathrm{~N}_{1}\right)$ pdmog pandemic and to compare these results with data obtained by the cycEVA study, to explore the feasibility and validity of monitoring the effectiveness of the influenza vaccine in Spain using surveillance data.

\section{Methods}

\section{The Spanish Influenza Sentinel Surveillance} System and cycEVA study

SISS was implemented more than a decade ago, in accordance with established national and international guidelines [18]. The system meets the surveillance requirements (European Influenza Surveillance Scheme, ECDC) regarding the minimum population covered $(>1 \%)$ and representativeness in terms of age, sex and degree of urbanisation [19].

The SISS comprises 17 networks of sentinel physicians (general practitioners and paediatricians) in 17 of the 19 Spanish regions as well as network-affiliated laboratories, including the National Influenza Reference Laboratory (National Centre for Microbiology, World Health Organization National Influenza Centre in Madrid). Sentinel physicians report cases of influenzalike illness (ILI) detected in their reference populations on a weekly basis according to a definition that is based on the EU ILI case definition [20].

For influenza surveillance, sentinel physicians systematically swab (nasal or nasopharyngeal) the first two patients presenting with ILI each week and send the swabs to the network-affiliated laboratories for influenza virus detection.

The information collected in the SISS includes the patient's sex, age, symptom onset date, swabbing date, clinical symptoms, virological information (type and subtype detected and strain characterisation), chronic conditions (i.e. chronic cardiovascular diseases, chronic pulmonary diseases, congenital or acquired immunodeficiency, diabetes mellitus, chronic hepatic disease and chronic renal disease) and risk factors (i.e. pregnancy (in women aged 15-44 years) and morbid obesity (defined as body mass index (BMI) $\geq 40$ $\mathrm{kg} / \mathrm{m} 2)$ ).

Vaccination status is collected as a dichotomous variable (yes/no); this information is collected either by asking the patient (or parent/guardian if the patient is too young) whether they have received the current influenza seasonal vaccine $\geq 14$ days before the onset of symptoms or from sentinel physician records.

The data are entered weekly by each regional sentinel network in a web-based application and analysed centrally by the National Centre of Epidemiology in Madrid to provide timely information on the evolving influenza activity in Spanish regions and at the national level [15] Physicians from sentinel networks participating in the cycEVA study collect additional information from patients, including date of vaccination, type of vaccine, previous seasonal influenza vaccination and information on confounding factors $[8,21]$.

\section{Study design and population}

To measure influenza VE, we conducted two test-negative case-control studies on laboratory-confirmed influenza cases during the 2010/11, 2011/12 and 2012/13 influenza seasons using surveillance data (SISS) and data from the cycEVA study. Most of the patients included in the cycEVA analysis were also included in the SISS analysis, but the information collected in cycEVA was more exhaustive and accurate. The study period used was the same as that previously evaluated in the cycEVA study, i.e. the epidemic weeks of each season: week 502010 to week 112011 for the 2010/11 season, week 502011 to week 142012 for the 2011/12 season, and week 512012 to week 172013 for the $2012 / 13$ season.

The study population using data from the SISS comprised all patients with ILI who consulted sentinel physicians belonging to the SISS. The first two ILI patients each week were swabbed and tested for influenza virus. The targeted vaccination groups were as follows: individuals older than 59 or 64 years (depending on the Spanish region), individuals with at least one chronic condition (i.e. cardiovascular disease, chronic pulmonary disease, congenital or acquired immunodeficiency, diabetes mellitus, hepatic disease or renal disease), pregnant women and/or morbidly obese individuals $(B M I \geq 40 \mathrm{~kg} / \mathrm{m} 2)$.

Cases were defined as patients with ILI with laboratory-confirmed influenza infection, as determined by reverse transcription (RT)-PCR analysis of samples obtained from respiratory specimens and/or cell culture using the Madin-Darby canine kidney (MDCK) cell line. Controls were defined as patients with ILI with who tested negative for any influenza virus strain. 
Influenza VE was estimated by comparing the vaccination statuses of influenza virus-positive patients with those of influenza virus-negative patients.

The population, sampling protocol and definitions of cases and controls of the cycEVA study have been previously described $[8,21]$.

\section{Data analysis}

Analyses were performed for the study population and for the population targeted for vaccination. Influenza VE estimates were compared using SISS and cycEVA data $[8,21,22]$. We estimated seasonal influenza VE against laboratory-confirmed influenza with the predominant influenza viruses $A\left(\mathrm{H}_{1} \mathrm{~N}_{1}\right)$ pdmog, $A\left(\mathrm{H}_{3} \mathrm{~N}_{2}\right)$ and $B$ for the $2010 / 11,2011 / 12$ and $2012 / 13$ seasons [15], respectively. We also studied the protective effect of the seasonal influenza vaccine by age group using the same categories used by the I-MOVE network (0-14 years, 15-59 years and $\geq 60$ years) in the study population during the three seasons studied. We included in the analyses ILI patients with information available on vaccination status, laboratory confirmation of infection and swabbing date.

To reduce the risk of misclassification over time because of false-negative results, we restricted our analyses to ILI patients with a delay between symptom onset and swabbing: we included those swabbed less than eight days after symptom onset [23] in the 2010/11 and 2011/12 seasons and those swabbed less than four days after symptom onset in the $2012 / 13$ season. For the analysis using SISS data, a sensitivity analysis was also undertaken: if dates of onset and/or swabbing were missing (in $15-17 \%$ of patients) then the delay between symptom onset and swabbing was assumed to have been less than eight days ( $98 \%$ of the patients with complete information on dates of symptom onset and swabbing had a delay of less than eight days).

Baseline characteristics of cases and controls were compared using chi-squared or Fisher's exact tests, as appropriate. Chi-squared test was used to compare proportions and $p<0.05$ was considered to be statistically significant. Odds ratios (ORs) and their corresponding 95\% confidence intervals (CIs) were obtained. Influenza VE was calculated using $(1-O R) \times 100$. Logistic regression models were used to estimate the unadjusted and adjusted ORs. For both the cycEVA study and SISS data, we adjusted for age group, week of swabbing and sentinel region. A comparison between influenza VE estimates for the three influenza seasons studied was performed for each data source (SISS and cycEVA), using a linear regression fit and testing whether the slopes and intercepts were significantly different [24].

Statistical analyses were conducted using STATA/IC 12.1 (StataCorp., College Station, Texas).

This study was performed within the framework of Spanish influenza surveillance activities, with no personal data collected. The patients or patient/guardian provided verbal informed consent to participate in the study. Consequently, the study did not require the approval of the Human Research Ethics Committee.

\section{Results}

Influenza season and characteristics of patients with influenza-like illness

The three influenza seasons included in the study in Spain differed in the presentation time of the epidemic, the type and subtype of the dominant virus (Figure 1) and the concordance between the vaccine and circulating influenza strains. On the basis of data from the SISS (Figure $1 \mathrm{~A}$ ) and the cycEVA study (Figure 1B), the weekly number of laboratory-confirmed influenza cases of influenza and test-negative controls recruited into the studies followed the same progression as the weekly ILI incidence in the participating regions during the three seasons studied.

In the 2010/11 influenza season, influenza $A\left(\mathrm{H}_{1} \mathrm{~N}_{1}\right)$ pdmog predominantly circulated until the epidemic peak in week 2/2011 (240 ILI cases per 100,000 population), whereas influenza $B$ virus became predominant after the epidemic period. Both circulating viruses were antigenically similar to the vaccine strains. Influenza activity in Spain during the 2011/12 season was associated with a predominance of circulating subtype $\mathrm{A}\left(\mathrm{H}_{3} \mathrm{~N}_{2}\right)$ influenza virus and a lower contribution of influenza B virus, which emerged primarily after the influenza epidemic had peaked. The 2011/12 season was a late season, with the maximum peak of influenza activity occurring in mid-February 2012 (Figure 1) and with a limited match between the vaccine and the circulating strains. Influenza activity during the 2012/13 season also occurred late and peaked in February 2013. That season was clearly dominated by circulation of the influenza B/Yamagata lineage virus, co-circulating with both the $A\left(\mathrm{H}_{3} \mathrm{~N}_{2}\right)$ and the $A\left(\mathrm{H}_{1} \mathrm{~N}_{1}\right)$ pdmog influenza A subtypes (Figure 1), which were all antigenically similar to the vaccine strains [25].

The annual influenza vaccination campaign in Spain lasted from September to November during the three influenza seasons studied (Figure 1).

During those seasons, the number of physicians participating in the SISS ranged from 867 to 885 (including 225-236 paediatricians) covering a population of $2.2-2.6 \%$ of the total Spanish population, which was representative in terms of age, sex and degree of urbanisation (Table 1). Of ILI patients visiting physicians who reported to the SISS during the study period ( $n=48,000$ ), between 4,454 and 4,583 per season were swabbed and received laboratory confirmation of influenza virus infection, which ranged from $27 \%$ in the $2012 / 13$ season to $29 \%$ in the $2010 / 11$ season.

The percentage of patients with incomplete information on laboratory results, vaccination status or date of 


\section{FIGURE 2}

Adjusted influenza vaccine effectiveness of the seasonal trivalent vaccine against A(H1N1)pdm09 (2010/11 season), A(H3N2) (2011/12 season) and B influenza virus (2012/13 season) in the study population and target groups for vaccination ${ }^{\text {, }}$, Spanish Influenza Sentinel Surveillance System and cycEVA study, Spain

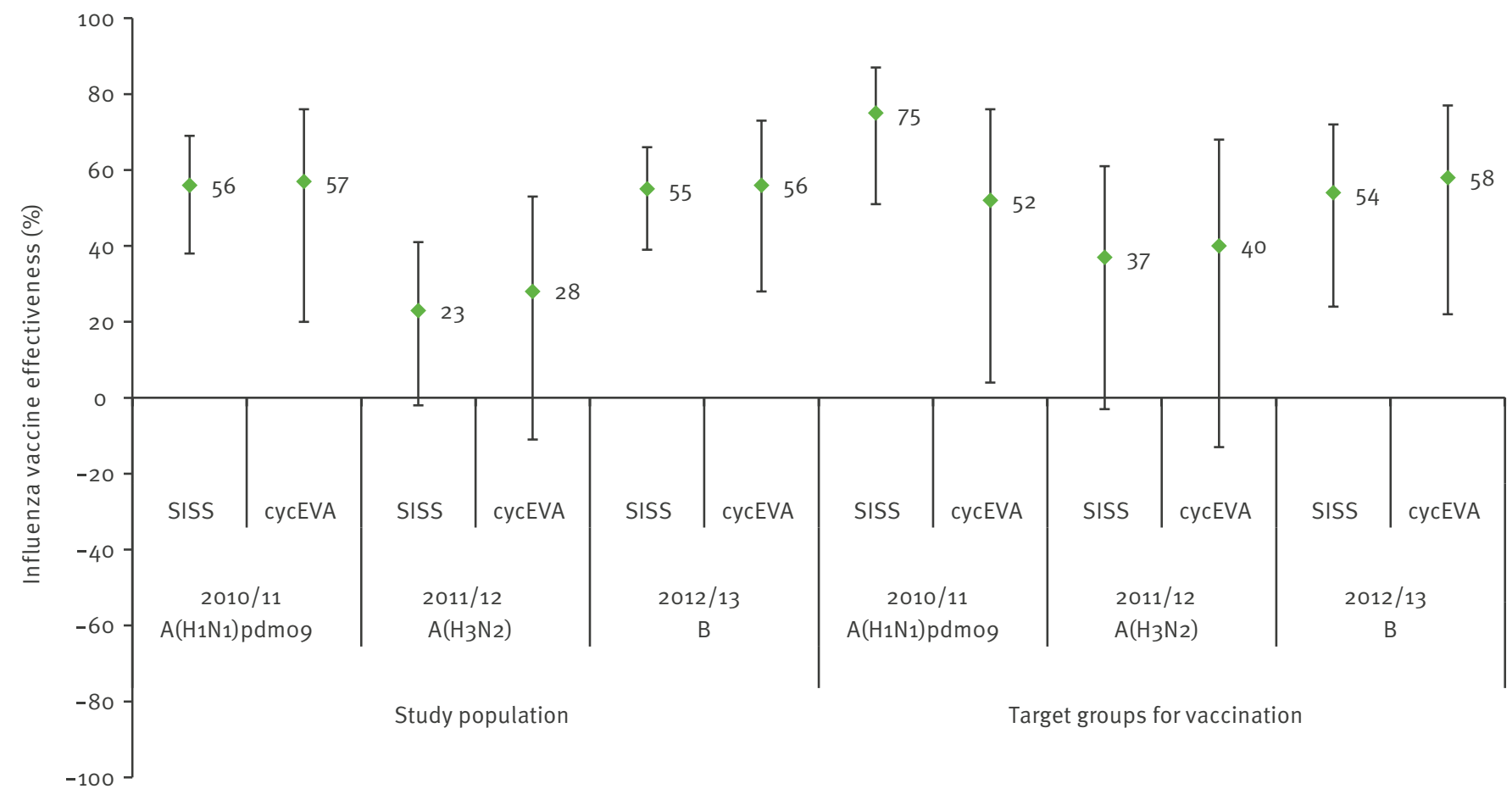

cycEVA study: the Spanish component of the Influenza Monitoring Vaccine Effectiveness (I-MOVE) network; SISS: Spanish Influenza Sentinel Surveillance System.

The bars represent $95 \%$ confidence intervals.

a Individuals older than 59 or 64 years (depending on the Spanish region), individuals with at least one chronic condition (i.e. cardiovascular disease, chronic pulmonary disease, congenital or acquired immunodeficiency, diabetes mellitus, hepatic disease or renal disease), pregnant women and/or morbidly obese individuals (body mass index $\geq 40 \mathrm{~kg} / \mathrm{m} 2$ ).

symptom onset ranged from $3 \%$ to $5 \%$ of the patients who were swabbed (Table 1): these patients were excluded from the analysis. We also excluded $15-17 \%$ of the patients who were swabbed because the swabbing date was unknown. In addition, patients with laboratory-confirmed influenza A virus infection without any subtype information were not included in the specific analysis of influenza VE against the predominant influenza strain (range of $3.6-6 \%$ of the recruited patients in the study period).

After applying the exclusion criteria, we included $93 \%$ of the recruited patients from the $2012 / 13$ season in the analysis (restricted to those patients swabbed less than four days after symptom onset) and $98 \%$ of the recruited patients for the $2010 / 11$ and $2011 / 12$ seasons (restricted to patients swabbed less than eight days after symptom onset) (Table 1).

From the patients who were included, we collected information on the presence of any chronic conditions or risk factors. This information was missing in 16-18\% of the patients in the SISS in the first two seasons studied and only $3 \%$ in $2012 / 13$ season (Table 1 ).
The number of GPs participating in the cycEVA study was 246, 231 and 239 for the 2010/11, 2011/12 and $2012 / 13$ seasons, respectively, covering $2.1 \%$ of the total population of the Spanish regions participating in the cycEVA study (Table 1). Compared with the number of cycEVA GPs, the number of participating sentinel physicians within the SISS was more than 3.5 times greater (Table 1). The SISS also included a higher proportion of paediatricians, averaging $26 \%$ in the three seasons compared with $19 \%$ in the cycEVA study ( $p<0.01$ ) (data not shown). Additionally, the number of patients with ILI determined using the SISS was three times higher than the number in the cycEVA study during the study period (Table 1). However, the information collected in the cycEVA study showed a lower percentage of incomplete information than that in the SISS; therefore, a lower percentage of recruited patients was excluded from the analysis (ranging from $0.1 \%$ to $5 \%$, compared with $24-29 \%$ for the SISS). Information regarding possible confounding factors, such as the presence of any chronic conditions or risk factors, was also more comprehensive in the cycEVA study, with none of the recruited patients having incomplete data during the last two seasons of the study period (2011/12 and 2012/13). 
TABLE 1

Spanish Influenza Sentinel Surveillance System and cycEVA study data, 2010/11, 2011/12 and 2012/13 seasons, Spain

\begin{tabular}{|c|c|c|c|c|c|c|}
\hline \multirow{2}{*}{ Characteristic } & \multicolumn{2}{|c|}{$\begin{array}{c}2010 / 11 \\
\text { influenza season }^{a}\end{array}$} & \multicolumn{2}{|c|}{$\begin{array}{c}2011 / 12 \\
\text { influenza season }^{b}\end{array}$} & \multicolumn{2}{|c|}{$\begin{array}{c}2012 / 13 \\
\text { influenza seasonc }\end{array}$} \\
\hline & SISS & cycEVA & SISS & cycEVA & SISS & CycEVA \\
\hline Number of participating Spanish regions & 17 & 7 & 17 & 7 & 17 & 7 \\
\hline $\begin{array}{l}\text { Number of participating GPs (percentage } \\
\text { population covered) }\end{array}$ & $885(2.6)$ & $246(2.1)$ & $877(2.4)$ & $231(2.1)$ & $867(2.2)$ & $239(2.1)$ \\
\hline Number of ILI patients reported & 15,302 & 1,376 & 16,286 & 1,471 & 16,486 & 1,471 \\
\hline Number of ILI patients swabbed (\%) ${ }^{e}$ & $4,468(29)$ & $1,376(100)$ & $4,583(28)$ & $1,471(100)$ & $4,454(27)$ & $1,471(100)$ \\
\hline \multicolumn{7}{|l|}{ Exclusions $(\mathrm{n}(\%))^{\mathrm{fz}}$} \\
\hline Laboratory result missing & $228(5.1)$ & $0(0.0)$ & $151(3.3)$ & $14(0.9)$ & $184(4.1)$ & $7(0.5)$ \\
\hline Vaccination status missing & $130(2.9)$ & $1(0.07)$ & $131(2.9)$ & $0(0.0)$ & $151(3.4)$ & $0(0.0)$ \\
\hline Date of symptom onset missing & $234(5.2)$ & $0(0.0)$ & $198(4 \cdot 3)$ & $0(0.0)$ & $14(0.3)$ & $0(0.0)$ \\
\hline Date of swabbing missing & $778(17)$ & $0(0.0)$ & $686(15)$ & $0(0.0)$ & $753(17)$ & $0(0.0)$ \\
\hline \multicolumn{7}{|c|}{ Information on patients included in the analysis $(n(\%))^{f}$} \\
\hline $\begin{array}{l}\text { Swabbing restriction: patients with swabbing } \\
\text { delay }<8 \text { days }^{5}\end{array}$ & $3,180(98)$ & $1,369(99)$ & $3,484(98)$ & $1,446(98)$ & $3,357(91)$ & $1,432(97)$ \\
\hline Missing information on chronic conditions $s^{h, i}$ & $571(18)$ & $280(20)$ & $541(16)$ & $0(0.0)$ & $88(2.0)$ & $2(0.13)$ \\
\hline Missing information on risk factors ${ }^{\mathrm{h}, \mathrm{j}}$ & $574(18)$ & $83(6.0)$ & $1,020(29)$ & $0(0.0)$ & $615(18)$ & $1(0.07)$ \\
\hline Genetic characterisation of influenza virusesk & $274(11)$ & $119(15)$ & $422(14)$ & $145(16)$ & $447(17)$ & $142(16)$ \\
\hline $\begin{array}{l}\text { Patients with swabbing delay }<8 \text { days } s^{g} \text { included } \\
\text { in the subtype-/type-specific analysis }\end{array}$ & $2,480(78)$ & $1,165(85)$ & $3,189(92)$ & 1,325 (92) & $2,875(86)$ & $1,225(86)$ \\
\hline
\end{tabular}

CycEVA study: the Spanish component of the Influenza Monitoring Vaccine Effectiveness (I-MOVE) network; GP: general practitioner; ILI: influenza-like illness; SISS: Spanish Influenza Sentinel Surveillance System.

a Week 502010 to week 122011.

b Week 502011 to week 142012.

Week 512012 to week 172013.

d Of the total Spanish population for the SISS and of the population of the Spanish regions participating in the cycEVA study.

e Of the reported patients.

of the swabbed patients.

$g$ Patients with missing date of swabbing not included.

h Of patients with swabbing delay $<8$ days.

' Defined as diabetes mellitus, cardiovascular disease, chronic pulmonary disease, renal disease, hepatic disease, congenital or acquired immunodeficiency.

Pregnancy (women 15-44 years-old) and morbid obesity (defined as body mass index $>40 \mathrm{~kg} / \mathrm{m}^{2}$ ).

Of the total laboratory-confirmed influenza cases.

$A\left(\mathrm{H}_{1} \mathrm{~N}_{1}\right)$ pdmog in 2010/11 season, $\mathrm{A}\left(\mathrm{H}_{3} \mathrm{~N}_{2}\right)$ in $2011 / 12$ season and $B$ in $2012 / 13$ season.

Genetic sequencing of the haemagglutinin gene of the circulating influenza viruses isolated from patients in the SISS increased over the seasons studied, from 274 to 447 influenza strains, accounting for $11 \%$ and $17 \%$ of the total number of laboratory-confirmed influenza cases reported during the first and last seasons, respectively. The proportion of characterised viruses in the cycEVA study (among those included in the analysis) was similar to that in the SISS, with $16 \%$ of the viruses characterised in the last two seasons (2011/12 and 2012/13) studied (Table 1).

Taking into account that we estimated seasonal influenza VE against laboratory-confirmed influenza due to the predominant influenza viruses $A\left(\mathrm{H}_{1} \mathrm{~N}_{1}\right)$ pdmog, $A\left(\mathrm{H}_{3} \mathrm{~N}_{2}\right)$, and $B$, we finally included SISS data of 2,480 , 3,189 , and 2,707 patients from the $2010 / 11,2011 / 12$ and $2012 / 13$ seasons, respectively, in the analysis. The sample obtained from the cycEVA study was 


\section{TABLE 2}

Characteristics of laboratory-confirmed influenza cases and test-negative controls in the study population, Spanish Influenza Sentinel Surveillance System, 2010/11, 2011/12 and 2012/13 seasons, Spain

\begin{tabular}{|c|c|c|c|c|c|c|c|c|c|}
\hline \multirow{3}{*}{ Characteristic } & \multicolumn{3}{|c|}{$2010 / 11$ Influenza season $(n=2,480)$} & \multicolumn{3}{|c|}{$2011 / 12$ Influenza season $(n=3,189)$} & \multicolumn{3}{|c|}{$2012 / 13$ influenza season $(n=2,707)$} \\
\hline & Controls & $\begin{array}{c}\mathrm{A}\left(\mathrm{H}_{1} \mathrm{~N}_{1}\right) \mathrm{pdm} \text { o9 } \\
\text { cases }\end{array}$ & \multirow{2}{*}{$\begin{array}{l}P \\
\text { value }^{d, e}\end{array}$} & Controls & $\mathrm{A}\left(\mathrm{H}_{3} \mathrm{~N}_{2}\right)$ cases & \multirow{2}{*}{$\begin{array}{c}\mathrm{P} \\
\text { value }^{\mathrm{d}, \mathrm{f}}\end{array}$} & Controls & B cases & \multirow{2}{*}{$\begin{array}{c}P \\
\text { value }^{\mathrm{d}, \mathrm{g}}\end{array}$} \\
\hline & $\mathrm{n} / \mathrm{N}(\%)^{\mathrm{a}}$ & $\mathrm{n} / \mathrm{N}(\%)^{\mathrm{a}}$ & & $\mathrm{n} / \mathrm{N}(\%)^{\mathrm{b}}$ & $\mathrm{n} / \mathrm{N}(\%)^{\mathrm{b}}$ & & $\mathrm{n} / \mathrm{N}(\%)^{\mathrm{c}}$ & $\mathrm{n} / \mathrm{N}(\%)^{\mathrm{c}}$ & \\
\hline $\begin{array}{l}\text { Median age } \\
\text { (range years) }\end{array}$ & $22(0-95)$ & $26(0-87)$ & 0.036 & $26(0-88)$ & $31(0-93)$ & 0.013 & $27(0-97)$ & $17(0-84)$ & 0.009 \\
\hline \multicolumn{10}{|c|}{ Age group in years } \\
\hline $0-4$ & $184 / 1,319(14)$ & $132 / 1,161(11)$ & \multirow{4}{*}{0.000} & $198 / 1,221(16)$ & $330 / 1,968(17)$ & \multirow{4}{*}{0.021} & $210 / 1,151(18)$ & $185 / 1,556(12)$ & \multirow{4}{*}{0.000} \\
\hline $5-14$ & $359 / 1,319(27)$ & $269 / 1,161(23)$ & & $276 / 1,221(23)$ & $451 / 1,968(23)$ & & $266 / 1,151(23)$ & $564 / 1,156(36)$ & \\
\hline $15-64$ & $694 / 1,319(53)$ & $733 / 1,161(63)$ & & $678 / 1,221(55)$ & $1017 / 1,968(52)$ & & $593 / 1,151(52)$ & $752 / 1,556(48)$ & \\
\hline$\geq 65$ & $78 / 1,319(5.9)$ & $25 / 1,161(2.2)$ & & $69 / 1,221(5.7)$ & $169 / 1,968(8.6)$ & & $81 / 1,151(7.0)$ & $53 / 1,556(3.4)$ & \\
\hline $\begin{array}{l}\text { Missing } \\
\text { information }\end{array}$ & 4/1,319 (0.3) & $2 / 1,161(0.2)$ & 0.800 & $0 / 1,221(0.0)$ & $1 / 1,968(0.05)$ & 0.000 & $1 / 1,151$ (0.09) & $2 / 1,556(0.1)$ & 0.793 \\
\hline \multicolumn{10}{|l|}{ Sex } \\
\hline Male & $665 / 1,319(50)$ & $593 / 1,161(51)$ & 0.820 & $638 / 1,221(52)$ & 949/1,968 (48) & 0.081 & $600 / 1,151(52)$ & $772 / 1,556(50)$ & 0.382 \\
\hline $\begin{array}{l}\text { Missing } \\
\text { information }\end{array}$ & $5 / 1,319(0.4)$ & $6 / 1,161(0.5)$ & 0.986 & $3 / 1,221(0.2)$ & 4/1,968 (0.2) & 0.000 & 4/1,151 (0.3) & 4/1,556 (0.3) & 1.000 \\
\hline \multicolumn{10}{|c|}{ Chronic conditions } \\
\hline $\begin{array}{l}\text { Any chronic } \\
\text { condition }^{\mathrm{h}} \\
\text { reported }\end{array}$ & $130 / 1,319$ (10) & $88 / 1,161(7.6)$ & 0.000 & $139 / 1,221(11)$ & $195 / 1,968(10)$ & 0.135 & $165 / 1,151(14)$ & $169 / 1,556(11)$ & 0.025 \\
\hline $\begin{array}{l}\text { Missing } \\
\text { information }\end{array}$ & $229 / 1,319(17)$ & $294 / 1,161(25)$ & 0.000 & $182 / 1,221(15)$ & $338 / 1,968$ (17) & 0.130 & $27 / 1,151(2.3)$ & $38 / 1,556(2.4)$ & 0.839 \\
\hline \multicolumn{10}{|l|}{ Risk factors } \\
\hline $\begin{array}{l}\text { Any risk } \\
\text { factor } \\
\text { reportedi }\end{array}$ & $31 / 1,319(2.3)$ & $21 / 1,161(1.8)$ & 0.000 & $22 / 1,221(1.8)$ & $39 / 1,968(2.0)$ & 0.936 & $14 / 1,151(1.2)$ & $17 / 1,556(1.1)$ & 0.753 \\
\hline $\begin{array}{l}\text { Missing } \\
\text { information }\end{array}$ & $432 / 1,319(33)$ & $478 / 1,161(41)$ & 0.000 & $\begin{array}{c}364 / 1,221 \\
(30)\end{array}$ & $587 / 1,968(30)$ & 0.998 & $209 / 1,151(18)$ & $267 / 1,556(17)$ & 0.518 \\
\hline \multicolumn{10}{|l|}{ Vaccine status ${ }^{i}$} \\
\hline All ages & $155 / 1,319(12)$ & $64 / 1,161(5.5)$ & 0.000 & $149 / 1,221(12)$ & $222 / 1,968(11)$ & 0.430 & $142 / 1,151(12)$ & $83 / 1,556(5.3)$ & 0.000 \\
\hline \multicolumn{10}{|c|}{ Vaccine eligibility } \\
\hline $\begin{array}{l}\text { Eligible for } \\
\text { vaccination }\end{array}$ & $66 / 183(36)$ & $27 / 128(21)$ & 0.005 & 77/173 (44) & $117 / 284(41)$ & 0.487 & $72 / 176(41)$ & $39 / 182(21)$ & 0.000 \\
\hline
\end{tabular}

$P$ values in bold are statistically significant.

a Cases and controls recruited between week 502010 and week 122011 and with an interval between symptom onset and swabbing of less than eight days.

b Cases and controls recruited between week 522011 and week 142012 and with an interval between symptom onset and swabbing of less than eight days.

c Cases and controls recruited between week 512012 and week 172013 and with an interval between symptom onset and swabbing of less than four days.

d Non-parametric test of the median or chi-squared test or Fisher's exact test, when appropriate.

e $A\left(\mathrm{H}_{1} \mathrm{~N}_{1}\right)$ pdmog cases vs controls $\mathrm{p}$ value.

$\mathrm{A}\left(\mathrm{H}_{3} \mathrm{~N}_{2}\right)$ cases vs controls $\mathrm{p}$ value.

g $B$ cases vs controls $p$ value.

h Defined as diabetes mellitus, cardiovascular disease, chronic pulmonary disease, renal disease, hepatic disease, congenital or acquired immunodeficiency.

Defined as pregnancy (women 15-44 years-old) and/or morbid obesity (body mass index $\geq 40 \mathrm{~kg} / \mathrm{m}^{2}$ ).

Only patients with known vaccination status were included in the analysis.

1.8-2.4 times smaller in size $(1,165,1,325$ and 1,192 patients, respectively). Among the SISS patients analysed, we identified 1,319 controls and 1,161 $\mathrm{A}\left(\mathrm{H}_{1} \mathrm{~N}_{1}\right)$ pdmog cases for the 2010/11 season; 1,221 controls and $1,968 \mathrm{~A}\left(\mathrm{H}_{3} \mathrm{~N}_{2}\right)$ cases for the $2011 / 12$ season; and
1,151 controls and 1,556 B cases for the $2012 / 13$ season (Table 2).

The main characteristics of cases and controls during the study period are shown for the SISS (Table 2) and 
Characteristics of laboratory-confirmed influenza cases and test-negative controls in the study population, cycEVA study, 2010/11, 2011/012 and 2012/13 seasons, Spain

\begin{tabular}{|c|c|c|c|c|c|c|c|c|c|}
\hline \multirow{3}{*}{ Characteristic } & \multicolumn{3}{|c|}{$2010 / 11$ Influenza season $(n=1,165)$} & \multicolumn{3}{|c|}{$2011 / 12$ Influenza season $(n=1,348)$} & \multicolumn{3}{|c|}{$2012 / 13$ influenza season $(n=1,192)$} \\
\hline & Controls & $\begin{array}{c}\mathrm{A}\left(\mathrm{H}_{1} \mathrm{~N}_{1}\right) \\
\text { pdmog cases }\end{array}$ & \multirow{2}{*}{ P value ${ }^{d, e}$} & Controls & $\begin{array}{c}\mathrm{A}\left(\mathrm{H}_{3} \mathrm{~N}_{2}\right) \\
\text { cases }\end{array}$ & \multirow[t]{2}{*}{ P value ${ }^{d, f}$} & Controls & B cases & \multirow[t]{2}{*}{ P value ${ }^{\mathrm{d}, \mathrm{g}}$} \\
\hline & $\mathrm{n} / \mathrm{N}(\%)^{\mathrm{a}}$ & $\mathrm{n} / \mathrm{N}(\%)^{\mathrm{a}}$ & & $\mathrm{n} / \mathrm{N}(\%)^{\mathrm{b}}$ & $\mathrm{n} / \mathrm{N}(\%)^{\mathrm{b}}$ & & $\mathrm{n} / \mathrm{N}(\%)^{c}$ & $\mathrm{n} / \mathrm{N}(\%)^{\mathrm{c}}$ & \\
\hline $\begin{array}{l}\text { Median age in } \\
\text { years (range) }\end{array}$ & $32(0-95)$ & $31(0-85)$ & 0.493 & $33(0-87)$ & $36(0-93)$ & 0.067 & $32(0-85)$ & $31(0-84)$ & 0.711 \\
\hline \multicolumn{10}{|c|}{ Age group (years) } \\
\hline $0-4$ & 46/591 (8) & 43/574 (7) & \multirow{4}{*}{0.000} & 41/528 (8) & $96 / 820(12)$ & \multirow{4}{*}{0.001} & $75 / 535(14)$ & $68 / 657(10)$ & \multirow{4}{*}{0.000} \\
\hline 5-14 & $111 / 591(19)$ & $73 / 574(13)$ & & $90 / 528(17)$ & $133 / 820(16)$ & & $102 / 535(19)$ & $197 / 657$ (30) & \\
\hline $15-64$ & $387 / 591(65)$ & $441 / 574(77)$ & & $358 / 528(68)$ & $491 / 820(60)$ & & $323 / 535(60)$ & $362 / 657(55)$ & \\
\hline$\geq 65$ & 47/591 (8) & $17 / 574$ (3) & & $39 / 528(7)$ & $100 / 820(12)$ & & $35 / 535(7)$ & $30 / 657(5)$ & \\
\hline $\begin{array}{l}\text { Missing } \\
\text { information }\end{array}$ & o/591 (o) & o/574 (o) & NA & $0 / 528(0)$ & $0 / 820(0)$ & NA & $0 / 535(0)$ & $0 / 657(0)$ & NA \\
\hline \multicolumn{10}{|l|}{ Sex } \\
\hline Male & $293 / 591(50)$ & $271 / 574(47)$ & 0.419 & $265 / 528(50)$ & $402 / 820(49)$ & 0.676 & $277 / 535(52)$ & $333 / 657(51)$ & 0.708 \\
\hline $\begin{array}{l}\text { Missing } \\
\text { information }\end{array}$ & o/591 (o) & o/574 (o) & NA & $0 / 528(0)$ & $0 / 820(0)$ & NA & o/535 (o) & $0 / 657(0)$ & NA \\
\hline \multicolumn{10}{|c|}{ Chronic conditions } \\
\hline $\begin{array}{l}\text { Any chronic } \\
\text { condition } \\
\text { reported }\end{array}$ & 79/591 (13) & $60 / 591(10)$ & 0.174 & $78 / 528(15)$ & $117 / 820(14)$ & 0.797 & $103 / 535$ (19) & $96 / 657(15)$ & 0.033 \\
\hline $\begin{array}{l}\text { Missing } \\
\text { information }\end{array}$ & $126 / 591(21)$ & $112 / 574(20)$ & 0.673 & $0 / 528(0)$ & $0 / 820(0)$ & NA & o/535 (o) & $0 / 657(0)$ & NA \\
\hline \multicolumn{10}{|l|}{ Risk factors } \\
\hline $\begin{array}{l}\text { Any risk factor } \\
\text { reported }^{\mathrm{h}}\end{array}$ & $13 / 591(2.2)$ & $7 / 574(1.2)$ & 0.091 & $9 / 528(1.7)$ & $18 / 820(2.2)$ & 0.530 & 9/535 (1.7) & $9 / 657(1.4)$ & 0.490 \\
\hline $\begin{array}{l}\text { Missing } \\
\text { information }\end{array}$ & $30 / 591(5)$ & $44 / 574(8)$ & 0.037 & $0 / 528(0)$ & $0 / 820(0)$ & NA & $1 / 535(0.2)$ & $0 / 657(0)$ & 0.000 \\
\hline \multicolumn{10}{|l|}{ Vaccine status $^{i}$} \\
\hline All ages & 63/591 (11) & $23 / 574(4)$ & 0.000 & 69/528 (13) & $111 / 820(14)$ & 0.805 & $56 / 535(10)$ & $31 / 657(5)$ & 0.000 \\
\hline \multicolumn{10}{|c|}{ Vaccine eligibility } \\
\hline $\begin{array}{l}\text { Eligible for } \\
\text { vaccination }\end{array}$ & $57 / 184(31)$ & $20 / 135(15)$ & 0.001 & $50 / 123(41)$ & $88 / 226(39)$ & 0.755 & 45/133（34） & 26/139 (19) & 0.005 \\
\hline
\end{tabular}

cycEVA study: the Spanish component of the Influenza Monitoring Vaccine Effectiveness (I-MOVE) network; NA: not applicable.

$P$ values in bold are statistically significant.

a Cases and controls recruited between week 502010 and week 122011 and with an interval between symptom onset and swabbing of less than eight days.

b Cases and controls recruited between week 522011 and week 142012 and with an interval between symptom onset and swabbing of less than eight days.

c Cases and controls recruited between week 512012 and 172013 and with an interval between symptom onset and swabbing of less than four days.

d Non parametric test of the median or chi-squared test or Fisher's exact test, when appropriate.

e $\mathrm{A}\left(\mathrm{H}_{1} \mathrm{~N}_{1}\right)$ pdmog cases vs controls $\mathrm{p}$ value.

$\mathrm{A}\left(\mathrm{H}_{3} \mathrm{~N}_{2}\right)$ cases vs controls $\mathrm{p}$ value.

$\mathrm{g}$ B cases vs controls $\mathrm{p}$ value.

h Defined as pregnancy (women 15-44 years-old) and/or morbid obesity (body mass index $\geq 40 \mathrm{~kg} / \mathrm{m}^{2}$ ).

Only patients with known vaccination status were included in the analysis.

cycEVA study (Table 3). Regarding the main characteristics of the patients included in the analysis, overall, the most represented age group was $15-64$ year-olds, who accounted for $50-58 \%$ of all recruited patients from each season according to the SISS data (Table 2) and $57-71 \%$ according to the cycEVA data (Table 3 ).

\section{Vaccine effectiveness ${ }^{\star}$}

Adjusted influenza VE estimates for the study population were similar using data from the SISS and cycEVA study: $56 \%(95 \% \mathrm{Cl}: 38$ to 69$)$ and $57 \%(95 \% \mathrm{Cl}: 20$ to 76$), 23 \%(95 \% \mathrm{Cl}:-2$ to 41$)$ and $28 \%(95 \% \mathrm{Cl}:-11$ to 53$)$, and $55 \%(95 \% \mathrm{Cl}: 39$ to 66$)$ and $56 \%(95 \% \mathrm{Cl}$ : 
28 to 73 ) in the $2010 / 11,2011 / 12$ and $2012 / 13$ influenza seasons, respectively (Figure 2). Adjusted influenza VE estimates in the population targeted for vaccination were also consistent using both data sources, although the SISS point estimates were slightly higher for the $2010 / 11$ season $(75 \%(95 \% \mathrm{Cl}: 51$ to 87$)$ ) than the $52 \%(95 \% \mathrm{Cl}: 4$ to 76$)$ in the cycEVA study (Figure 2). The comparison analyses showed no statistically significant differences in the slopes of influenza VE estimates along the three studied seasons for the two data sources, either for the study population $\left(\mathrm{F}_{5}^{1}=0.03\right.$; $\mathrm{p}=0.88$ ) or for the population targeted for vaccination $\left(\mathrm{F}_{5}^{1}=0.51 ; \mathrm{p}=0.55\right)$.

On the assumption that patients with missing dates of onset and/or swabbing were swabbed within eight days from symptom onset, we estimated VE for the study population to be $64 \%(95 \% \mathrm{Cl}: 51$ to 73$), 9 \%$ (95\% Cl: -16 to 27 ) and 60\% (95\% Cl: 47 to 70 ) for the 2010/11, 2011/12 and 2012/13 seasons, respectively. For the target groups for vaccination, VE estimates were $70 \%(95 \% \mathrm{Cl}: 48$ to 83$), 33 \%(95 \% \mathrm{Cl}:-1$ to 55$)$ and $62 \%(95 \% \mathrm{Cl}: 38$; to 77$)$ for the $2010 / 11,2011 / 12$ and $2012 / 13$ seasons, respectively.

The analysis by age group in the study population showed that influenza VE for patients aged 15-59 years and those older than 59 years were similar using data from either the SISS or cycEVA study (Table 4 ).

For patients aged 15-59 years, the VE estimates using both data sources ranged from $30 \%$ to $74 \%$, with a higher and optimal protective effect of the vaccine during the $2012 / 13$ season using the cycEVA study data (74\% (95\% Cl: 38 to 89 )) and lower but not statistically significant difference in the 2011/12 season with SISS data $(30 \%(95 \% \mathrm{Cl}:-8$ to 54$))$. For elderly patients (>59 years), adjusted VE estimates ranged from $42 \%$ to $72 \%$, with a higher and optimal protective effect of the vaccine during the $2012 / 13$ season using the cycEVA study data ( $72 \%$ ( $95 \% \mathrm{Cl}: 15$ to 91$)$ ). In general, the sample size was 1.7 to 2.4 times higher using SISS compared with cycEVA study data and, consequently, SISS-estimates by age group generally showed narrower confidence intervals (Table 4 ).

However, estimates from the two data sources for patients aged 0-14 years were not comparable. We did not find any protective effect of the vaccine using cycEVA study data; however, using SISS data, the VE estimates were $31 \%(95 \% \mathrm{Cl}:-17$ to 60$)$ and $57 \%(95 \%$ $\mathrm{Cl}: 22$ to 76 ) in 2011/12 and 2012/13, respectively. For the 2010/11 season, the adjusted VE estimates were identical for the two data sources (Table 4). Regarding sample size, using SISS data we included in the specific $0-14$ years analysis $2.6-5$ times more patients than with the cycEVA study data.

Lower VE estimates in each age group were generally observed during the late 2011/12 influenza season using both data sources (Table 4).

\section{Discussion}

Our estimates of influenza VE against laboratory-confirmed influenza using surveillance data were largely similar to those obtained from the observational cycEVA study $[8,21,22]$ and showed a moderate protective effect for the trivalent influenza seasonal vaccine during the study period.

For the 2010/11 season, adjusted VE estimates against the predominant $\mathrm{A}\left(\mathrm{H}_{1} \mathrm{~N}_{1}\right)$ pdmog influenza virus, was $56 \%$ and $57 \%$ using SISS and cycEVA, respectively, in line with those described by the I-MOVE network [26], the UK [27] and the Navarre region of Spain [28], which ranged from $55 \%$ to $62 \%$. Lower estimates against $\mathrm{A}\left(\mathrm{H}_{3} \mathrm{~N}_{2}\right)$ virus (23\% (SISS) and 25\% (cycEVA)) were also observed in the Navarre region (29\%) [29] and in the I-MOVE network (25\%) [30] during the late 2011/12 influenza season, as well as in previous $\mathrm{A}\left(\mathrm{H}_{3} \mathrm{~N}_{2}\right)$ dominant seasons (31\%) in Spain [31]. For the 2012/13 season, adjusted VE estimates against B virus were $56 \%$ and $62 \%$ using SISS and cycEVA, respectively, similar to those observed in the I-MOVE network [32].

\section{Limitations arising from surveillance versus research-oriented systems}

When studying the protective effect of the seasonal influenza vaccine among the groups targeted for vaccination, we observed some difference in the influenza VE point estimates using the SISS and cycEVA data, although they were not statistically significant. Some of these could have been caused by limitations arising from use of surveillance data, which will be described below.

The quality of the information collected by the SISS and the cycEVA study on exposure (influenza vaccination) and outcome (laboratory confirmation) was satisfactory, with low percentages of incomplete information in both systems (around 0-3.5\%) [11,33].

A more substantial limitation of our surveillance data was missing information on swabbing date (in $15-17 \%$ of recruited patients): this information is crucial when restricting the analysis according to time between symptom onset and swabbing, and helps to minimise the possibility of misclassification as false-negative RT-PCR results [23]. However, the sensitivity analyses, which included patients with missing dates of onset and/or swabbing, on the assumption that they were swabbed within eight days from symptom onset (as did $98 \%$ of the patients with complete information), showed VE estimates that differed by $4-8 \%$ and with narrower Cls. In spite of that, the differences were higher (14\%) for the study population for the 2011/12 season, a season characterised by a late epidemic peak and a limited match between the circulating $A\left(\mathrm{H}_{3} \mathrm{~N}_{2}\right)$ influenza virus and the vaccine strain, and in which the trivalent seasonal vaccine showed a lower protective effect compared with other influenza seasons [25].

SISS data also contained a high proportion of patients with missing co-morbidity data, which could bias VE 
estimates from the surveillance data. Although the SISS point estimates were only 7-8\% lower than those observed with cycEVA data during the last two seasons studied (Figure 2), the VE estimates using SISS could be overestimated for the $2010 / 11$ season (75\% compared with $52 \%$ with cycEVA for the target groups). This discrepancy could be related to a higher vaccine coverage for patients with information on chronic conditions/risk factors (included in analysis for the target groups) than for patients with missing information on chronic conditions/risk factors (not included in the analysis for the target groups), with coverage of $9 \%$ and $7 \%$, respectively $(p<0.05)$.

Results of a sensitivity analysis excluding patients with missing information on chronic conditions (data not shown) showed similar adjusted VE estimates (point differences ranged from $4 \%$ to $7 \%$ in $2010 / 11$ and 2011/12 and an exact point estimate of $55 \%$ in $2012 / 13)$. In addition, inclusion of the variable chronic conditions into the regression models did not significantly change VE estimates. Therefore, missing information on chronic conditions was unlikely to have biased our VE estimates using SISS data. Imputation techniques will be used in further analyses in order to adjust for missing values in key variables [34,35].

Another reason for the observed discrepancies between the results from the two data sources could be possible differences in the main characteristics of the study populations. The median age of patients in the SISS were 6-10 years younger than that of the patients in the cycEVA study.

Information on vaccine status was collected by the sentinel physicians based on patient self-report at the time of specimen submission, before the test result was known, thus minimising differential recall bias. Although this could generate a potential source of misclassification, studies in other settings have reported consistency between self-reported and registry-based influenza vaccination status $[36,37]$.

A more general limitation of the surveillance strategy is that the system does not currently collect the vaccination dates of patients. However, the likelihood of vaccination status misclassification within the SISS it is low since the seasonal influenza vaccination campaign usually finishes in Spain well before the beginning of the influenza season. Only unusual scenarios, such as influenza pandemics $[7,12]$ or when the influenza season starts early, would require a specific observational study to estimate influenza VE.

A further limitation of our study could arise from the fact that comparison of VE estimates was made among two data sources that are not mutually exclusive. Patients in the cycEVA study were a subset of SISS patients for whom GPs collected additional information on confounders and date of influenza vaccination.
We also have to be aware that the distribution of influenza virus strains might differ by time of the epidemic and region: this could explain certain differences in the VE estimates obtained in this study, which was focused on influenza VE against the predominant circulating influenza subtype.

Age-specific vaccination effectiveness estimates By age group, the SISS influenza VE estimates were quite similar to those from the cycEVA study for 15-59 age group $( \pm 10-13 \%)$, who comprised the most represented age group in both study populations, and for the elderly ( $\pm 5-12 \%$ ), except for the $2012 / 13$ season, with $19 \%$ points of difference between the SISS and cycEVA estimates.

In general, point estimates using the surveillance data were lower for both age groups compared with cycEVA study estimates. Differences in the estimates for elderly patients could be related to different swabbing practices (all patients in cycEVA study but the first two patients of any age each week in the SISS). However, both criteria for selecting patients for swabbing were recently shown to give similar influenza VE estimates [37]. Considering the difference in the extent of data collection for important confounders in elderly patients, the influenza VE estimates for this group could have been under estimated using the surveillance data. By improving the quality of information and the swabbing protocol in the future [30], we should be able to overcome the limited accuracy of our current influenza VE estimates for elderly patients using SISS data.

\section{Comparison with published data}

In general, our age-specific VE estimates were comparable to those in other European countries and regions. Point estimates for patients aged $15-59$ years were in the range of those described by the Navarre region, the I-MOVE network and the UK $[28,32,34]$. Point estimates lower than $50 \%$ in preventing $\mathrm{A}\left(\mathrm{H}_{3} \mathrm{~N}_{2}\right)$ infections in the late $2011 / 12$ season (30\% with SISS and $41 \%$ with cycEVA) were also described in patients younger than 65 years in the UK (19\%) [35] and the Navarre region (44\%) [29], although a higher protective effect was observed by the I-MOVE network (63\%) [30]. In addition, protective estimates against influenza B virus observed during the $2012 / 13$ season, $64 \%$ (SISS) and $74 \%$ (cycEVA), were comparable to the $64 \%$ observed by I-MOVE [32]. Our point estimates for elderly patients were in line with those published by the UK: $48 \%$ protection against $A\left(\mathrm{H}_{3} \mathrm{~N}_{2}\right)$ virus in the $2011 / 12$ season [35] (47\% (SISS), 42\% (cycEVA)) and higher protective effect against $B$ virus in $2012 / 13$ season (65\% in UK [34] vS $53 \%$ (SISS) and $72 \%$ (cycEVA)). In the $2010 / 11$ season, our VE estimates for elderly patients were lower than those from the I-MOVE network [26], 47-59\% vs $72 \%$. The differences observed could be related to differences in vaccine coverage, vaccine brands used, proportion of people with chronic conditions, and/or characteristics of influenza circulating strains. 
Adjusted influenza vaccine effectiveness of the seasonal trivalent vaccine against the predominant circulating influenza virus in the study population by age group, Spanish Influenza Sentinel Surveillance System and cycEVA study, 2010/11, 2011/12 and 2012/13 influenza seasons, Spain

\begin{tabular}{|c|c|c|c|c|c|}
\hline $\begin{array}{l}\text { Influenza } \\
\text { season }\end{array}$ & $\begin{array}{l}\text { Age group } \\
\text { in years }\end{array}$ & Data source & $\begin{array}{c}\text { Total number of cases/ } \\
\text { controls }\end{array}$ & $\begin{array}{c}\text { Number of } \\
\text { vaccinated cases/ } \\
\text { vaccinated controls }\end{array}$ & $\begin{array}{l}\text { Adjusted influenza } \\
\text { VE \% }(95 \% \mathrm{Cl})\end{array}$ \\
\hline \multirow{6}{*}{ 2010/11 } & \multirow{2}{*}{$0-14$} & SISS & $476 / 725$ & $20 / 58$ & $60(28 \text { to } 78)^{a}$ \\
\hline & & cycEVA & $116 / 157$ & $2 / 6$ & $60(-180 \text { to } 94)^{a}$ \\
\hline & \multirow{2}{*}{$15-59$} & SISS & $910 / 917$ & $35 / 76$ & $56(32 \text { to } 72)^{b}$ \\
\hline & & cycEVA & $419 / 358$ & $9 / 18$ & $43(-41 \text { to } 77)^{b}$ \\
\hline & \multirow{2}{*}{$\geq 60$} & SISS & $65 / 146$ & $24 / 65$ & $47(-23 \text { to } 78)^{c}$ \\
\hline & & cycEVA & $39 / 76$ & $12 / 39$ & $59(-19 \text { to } 76)^{c}$ \\
\hline \multirow{6}{*}{$2011 / 12$} & \multirow{2}{*}{$0-14$} & SISS & $781 / 474$ & $37 / 34$ & $31(-17 \text { to } 60)^{a}$ \\
\hline & & cycEVA & $229 / 128$ & $13 / 8$ & $2(-186 \text { to } 66)^{a}$ \\
\hline & \multirow{2}{*}{$15-59$} & SISS & $944 / 638$ & $59 / 51$ & $30(-8 \text { to } 54)^{b}$ \\
\hline & & cycEVA & $452 / 334$ & $21 / 22$ & $41(-16 \text { to } 70)^{b}$ \\
\hline & \multirow{2}{*}{$\geq 60$} & SISS & $242 / 109$ & $126 / 64$ & $47(3 \text { to } 72)^{c}$ \\
\hline & & cycEVA & $141 / 63$ & $77 / 39$ & $42(-29 \text { to } 74)^{c}$ \\
\hline \multirow{6}{*}{$2012 / 13$} & \multirow{2}{*}{$0-14$} & SISS & $749 / 476$ & $24 / 31$ & $57(22 \text { to } 76)^{\mathrm{a}}$ \\
\hline & & cycEVA & $265 / 177$ & $8 / 5$ & $-22(-305 \text { to } 63)^{a}$ \\
\hline & \multirow{2}{*}{$15-59$} & SISS & $701 / 560$ & $28 / 50$ & $64(40 \text { to } 79)^{\mathrm{b}}$ \\
\hline & & cycEVA & $334 / 305$ & $8 / 22$ & $74(38 \text { to } 89)^{\mathrm{b}}$ \\
\hline & \multirow{2}{*}{$\geq 60$} & SISS & $104 / 114$ & $31 / 60$ & $53(5 \text { to } 77)^{c}$ \\
\hline & & cycEVA & $58 / 53$ & $15 / 29$ & $72(15 \text { to } 91)^{c}$ \\
\hline
\end{tabular}

$\mathrm{CI}$ : confidence interval; cycEVA study: the Spanish component of the Influenza Monitoring Vaccine Effectiveness (I-MOVE) network; SISS: Spanish Influenza Sentinel Surveillance System; VE: vaccine effectiveness.

a Model adjusted for age group (0-4, 5-9 and 10-14 years), week of swabbing and Spanish region.

b Model adjusted for age group (15-40 and 41-59 years), week of swabbing and Spanish region.

Model adjusted for age group (60-69, 70-79, 80-89 and 90-105 years), week of swabbing and Spanish region.

Regarding the younger age groups, the SISS estimates were generally higher and more precise than the cycEVA estimates (the sample size of the cycEVA study being 2.5-5 times lower than for the SISS (Table 3)). Children monitored by the cycEVA study were under-represented compared with children in the SISS because of a low proportion of paediatricians among the participating sentinel physicians. We would therefore like to highlight the importance of performing influenza VE analysis by age group, especially in elderly patients, the main group recommended for vaccination. Age group-specific VE estimates shown in this study, although limited by a lack of precision with wide Cls that do not indicate statistical significance, will allow comparisons to be drawn among countries and regions and across seasons.

After five influenza seasons, the cycEVA study has become a system that is capable of rapidly providing and disseminating reliable information on influenza VE on an annual basis at the national and European level $[4-8,21,22,26,30,38]$. This research-oriented system was able to address ancillary questions, such as the effect of repeated annual vaccination, waning immunity, potential sources of bias and confounding (beyond what is collected by sentinel networks) and other issues. Currently, however, cost is a critical factor limiting the sustainability of this study.

Surveillance networks have been shown to be excellent frameworks for conducting influenza VE studies [10-12,39]. By using data from existing systems, surveillance networks are simpler and less expensive than observational studies. In addition, these networks have the advantage of larger sample sizes and being representative of the entire country. Larger sample sizes would allow increasingly important early in-season estimates to be carried out, when the virus is still circulating. This ability is crucial to contribute to the World Health Organization's seasonal vaccine composition consultation for deliberation on influenza viruses for vaccines for the next season [40] and supports the possibility of obtaining more accurate subgroup 
estimates (e.g. for target groups, virus types/subtypes and patient age groups).

Most of the limitations described in the current sentinel surveillance system could be overcome without costly modifications, including collection of the date of influenza vaccination and a reduction in the percentage of patients for whom there is incomplete information. To enhance the exhaustiveness of the data, we recommend emphasising to sentinel physicians the importance of improving the completeness of collected data at the regional level, with subsequent checking and validation of the data at the national level. Although strengthening the national influenza surveillance system does not require extra costs, it will require a long-term commitment of both human and material resources.

In conclusion, while acknowledging a role for a spectrum of VE research approaches, real-time monitoring of influenza VE using routine surveillance data is currently feasible in Spain and meets the minimum requirements described for influenza VE studies [41]. Enhancing the SISS by overcoming the drawbacks mentioned would optimise the system to provide reliable annual influenza VE estimates that guide national health authorities who implement influenza vaccination policies.

The sustainability of the well-established Spanish cycEVA study, as part of the I-MOVE network, is a crucial factor for more efficient validation and optimisation of the Spanish Influenza Sentinel Surveillance System.

\section{Acknowledgements}

We are grateful to the sentinel general practitioners and paediatricians and virologists participating in the cycEVA study, as well as to all professionals participating in the Spanish Influenza Sentinel Surveillance System. We thank the EpiConcept team and I-MOVE network for their valuable help in discussing cycEVA data and their fruitful comments.

\section{Conflict of interest}

None declared.

\section{Authors' contributions}

Silvia Jiménez-Jorge and Amparo Larrauri designed the study. Silvia Jiménez-Jorge wrote the first draft of the manuscript and undertook the statistical analysis. Silvia Jiménez-Jorge, Salvador de Mateo and Amparo Larrauri participated in data analysis, writing and interpretation of the results. Francisco Pozo and Inmaculada Casas established the microbiology database and contributed with the interpretation of the virological data. All authors participated in the interpretation of the data, contributed to the revision of the draft manuscript and approved the final version.
Members of the Spanish Influenza Sentinel Surveillance System

Physicians of the influenza sentinel surveillance networks of: Andalucía, Aragón, Asturias, Baleares, Canarias, Cantabria, Castilla la Mancha, Castilla y León, Cataluña, Comunidad Valenciana, Extremadura, Madrid, Navarre, País Vasco, La Rioja, Ceuta and Melilla; Epidemiologists from: Servicio de Vigilancia Epidemiológica y Evaluación, Consejería de Salud, Junta de Andalucía; Servicio de Vigilancia en Salud Pública, Dirección General de Salud Pública, Aragón; Dirección General de Salud Pública y Planificación, Consejería de Salud y Servicios Sanitarios, Asturias; Servicio de Epidemiología, Dirección General de Salut Pública, Baleares; Servicio de Epidemiología y Prevención, Consejería de Sanidad de Canarias; Sección de Epidemiología, Consejería de Sanidad, Trabajo y Servicios Sociales de Cantabria; Servicio de Epidemiología, Consejería de Sanidad de Castilla la Mancha; Dirección General de Salud Pública, Consejería de Sanidad de Castilla y León; Servicio de Vigilancia Epidemiológica, Dirección General de Salud Pública, Departament de Salut, Generalitat Catalunya; Àrea d'Epidemiologia, Conselleria de Sanitat, Comunitat Valenciana; Subdirección de Epidemiología, Dirección General de Salud Pública, Servicio Extremeño de Salud, Junta de Extremadura; Dirección Xeral Saúde Pública de Galicia; Dirección General de Atención Primaria de la Comunidad de Madrid; Servicio de Epidemiología, Consejería de Sanidad de la Región de Murcia; Instituto de Salud Pública de Navarra; Servicio de Vigilancia Epidemiológica, Consejería de Sanidad del País Vasco; Servicio de Epidemiología, Subdirección de Salud Pública de La Rioja; Sección de Vigilancia Epidemiológica, Consejería de Sanidad y Bienestar Social de Ceuta; Servicio de Epidemiología, Dirección General de Sanidad y Consumo, Consejería de Bienestar Social y Sanidad, Ciudad Autónoma de Melilla; Virologists from the following laboratories: National Influenza Reference Laboratory, WHO Influenza collaborating Centre (National Centre of Microbiology, ISCIII, Majadahonda-Madrid); WHO Influenza collaborating Centre, Facultad de Medicina de Valladolid; WHO Influenza collaborating Centre, Hospital Clínico de Barcelona; Hospital Virgen de las Nieves de Granada, Andalucía; Laboratorio del Hospital Miguel Servet de Zaragoza, Aragón; Laboratorio del Hospital Nuestra Senora de Covadonga de Oviedo, Asturias; Laboratorio del Hospital Son Dureta de Palma de Mallorca, Baleares; Laboratorio del Hospital Dr. Negrín de Las Palmas de Gran Canaria, Canarias; Laboratorio del Hospital Universitario Marqués de Valdecilla de Santander; Instituto Valenciano de Microbiología, Valencia, Comunitat Valenciana; Hospital San Pedro de Alcántara de Cáceres, Extremadura; Servicio de Microbiologia del Hospital Universitario Ramon y Cajal, Madrid; Laboratorio de la Clínica Universidad de Navarra, Pamplona, Navarra; Laboratorio de Microbiología del Hospital Donostia, País Vasco; Hospital San Pedro de la Rioja de Logroño, La Rioja; Laboratorio de Microbiología del Hospital de INGESA de Ceuta; Laboratorios de Microbioloxía CH de Vigo y de Ourense (Galicia), and Hospital Virgen de la Arrixaca de Murcia.

\section{* Authors' correction}

The adjusted influenza vaccine effectiveness estimates in the text for $2012 / 13$ for the study population obtained from SISS data and CycEVA study data were corrected. These changes were made on 21 July 2015, at the request of the authors.

\section{References}

1. World Health Organization. Vaccines against influenza WHO position paper - November 2012. Wkly Epidemiol Rec. 2012;87(47):461-76. Available from: http://www.who.int/ wer/2012/wer8747.pdf PMID:23210147 
2. Valenciano M, Ciancio B. I-MOVE study team. I-MOVE: a European network to measure the effectiveness of influenza vaccines. Euro Surveill. 2012;17(39):20281. PMID:23041022

3. European Centre for Disease Prevention and Control (ECDC). Protocol for case-control studies to measure pandemic and seasonal influenza vaccine effectiveness in the European Union and European Economic Area Member States. Stockholm: ECDC; 2009. Available from: http://ecdc.europa. eu/en/publications/Publications/0907 TED Influenza $\mathrm{AH}_{1} \mathrm{~N}_{1}$ Measuring Influenza Vaccine Effectiveness Protocol Case Control_Studies.pdf

4. Savulescu C, Jiménez-Jorge S, de Mateo S, Ledesma J, Pozo F, Casas I, et al. Effectiveness of the 2010/11 seasonal trivalent influenza vaccine in Spain: preliminary results of a casecontrol study. Euro Surveill. 2011;16(11):19820. PMID:21435330

5. Jimenez-Jorge S, de Mateo S, Pozo F, Casas I, Garcia CM Castilla J, et al. Early estimates of the effectiveness of the $2011 / 12$ influenza vaccine in the population targeted for vaccination in Spain, 25 December 2011 to 19 February 2012. Euro Surveill. 2012;17(12). pii: 20129. PMID: 22490308

6. Savulescu C, Valenciano M, de Mateo S, Larrauri A. cycEVA Study Team. Estimating the influenza vaccine effectiveness in elderly on a yearly basis using the Spanish influenza surveillance network--pilot case-control studies using different control groups, 2008-2009 season, Spain. Vaccine. 2010;28(16):2903-7. Available from: http://dx.doi. org/10.1016/j.vaccine.2010.01.054 PMID:20153351

7. Savulescu C, Jiménez-Jorge S, de Mateo S, Pozo F, Casas I, Breña PP, et al. Using surveillance data to estimate pandemic vaccine effectiveness against laboratory confirmed influenza $\mathrm{A}\left(\mathrm{H}_{1} \mathrm{~N}_{1}\right) 2009$ infection: two case-control studies, Spain, season 2009-2010. BMC Public Health. 2011;11(1):899-907. Available from: http://dx.doi.org/10.1186/1471-2458-11-899 PMID:22129083

8. Jiménez-Jorge S, Savulescu C, Pozo F, de Mateo S, Casas , Ledesma l, et al. Effectiveness of the 2010-11 seasonal trivalent influenza vaccine in Spain: cycEVA study. Vaccine. 2012;30(24):3595-602. Available from: http://dx.doi. org/10.1016/j.vaccine.2012.03.048 PMID:22472792

9. Girard MP, Katz JM, Pervikov Y, Hombach J, Tam JS. Report of the 7 th meeting on Evaluation of Pandemic Influenza Vaccines in Clinical Trials, World Health Organization, Geneva, 1718 February 2011. Vaccine. 2011;29(44):7579-86. Available from: http://dx.doi.org/10.1016/j.vaccine.2011.08.031 PMID:21856358

10. Kelly H, Carville K, Grant K, Jacoby P, Tran T, Barr I. Estimation of influenza vaccine effectiveness from routine surveillance data. PLoS ONE. 2009;4(3):e5079. Available from: http:// dx.doi.org/10.1371/journal.pone.0005079 PMID:19333374

11. Fleming DM, Andrews NJ, Ellis IS, Bermingham A, Sebastianpillai P, Elliot AJ, et al. Estimating influenza vaccine effectiveness using routinely collected laboratory data. J Epidemiol Community Health. 2010;64(12):1062-7. Available from: http://dx.doi.org/10.1136/jech.2009.093450 PMID:19910645

12. Skowronski DM, Janjua NZ, De SG, Winter AL, Dickinson JA, Gardy JL, et al. A Sentinel Platform to Evaluate Influenza Vaccine Effectiveness and New Variant Circulation, Canada 2010-2011 Season. Clin Infect Dis. 2012;55(3):332-42.10.1093/ cid/cis431

13. Valenciano M, Kissling E, Ciancio BC, Moren A. Study designs for timely estimation of influenza vaccine effectiveness using European sentinel practitioner networks. Vaccine. 2010;28(46):7381-8. Available from: http://dx.doi. org/10.1016/j.vaccine.2010.09.010 PMID:20851086

14. Larrauri A, de Mateo S; Spanish Influenza Sentinel Surveillance System. Characterisation of swabbing for virological analysis in the Spanish Influenza Sentinel Surveillance System during four influenza seasons in the period 2002-2006. Euro Surveill. 2007;12(5):706. Available from: http://www.eurosurveillance. org/images/dynamic/EM/V12No5/art706.pdf PMID:17991396

15. Instituto de Salud Carlos III. Informes anuales y semanales de Vigilancia de la Gripe en España. Sistema de Vigilancia de la Gripe en España. [Annual and weekly national influenza reports. Spanish Influenza Sentinel Surveillance System]. Madrid: Centro Nacional de Epidemiología Instituto de Salud Carlos III; 2012. [Accessed 5 May 2015]. Spanish. Available from: http://www.isciii.es/cne-gripe-infsemanal

16. Larrauri A, Jiménez-Jorge S, de Mateo Ontañón S, Pozo Sánchez F, Ledesma J, Casas Flecha I, et al. Epidemiology of the 2009 influenza pandemic in Spain. The Spanish Influenza Surveillance System. Enferm Infecc Microbiol Clin. 2012;30(Suppl 4):2-9. Available from: http://dx.doi. org/10.1016/S0213-005X(12)70098-8 PMID:23116786

17. Lopez-Perea N, Delgado C, Jimenez-Jorge S, Simón Méndez L, De Mateo S, Larrauri A. Swabbing characterization for virological confirmation in Spanish Influenza Surveillance
System (SISS): Pre-pandemic and pandemic/post-pandemic seasons. European Scientific Conference on Applied Infectious Disease Epidemiology (ESCAIDE), 6-8 November 2012 Edinburgh, United Kingdom. ESCAIDE reference number: 2012974. Abstract available from: http://ecdc.europa.eu/en/ ESCAIDE/past-ESCAIDE/Documents/ESCAIDE-2012-abstractbook.pdf

18. Aguilera JF, Paget WJ, van der Velden J. Development of a protocol to evaluate the quality of clinical influenza data collected by sentinel practitioners in Europe. Euro Surveill. 2002;7(11):374.

19. de Mateo S, Larrauri A, Mesonero C. [Influenza surveillance. New solutions to an old problem]. Gac Sanit. 2006;20(1):67-73. Spanish. PMID:16539998

20. European Commission. Commission Decision of 30 April 2009 amending Decision 2002/253/EC laying down case definitions for reporting communicable diseases to the Community network under Decision No 2119/98/EC of the European Parliament and of the Council. Luxembourg: Publications Office of the European Union. 1.5.2009. L 110. Available from: http:// eur-lex.europa.eu/LexUriServ/LexUriServ.do?uri=0J:L:2009:11 0:0058:0059:EN:PDF

21. Jiménez-Jorge S, de Mateo S, Delgado-Sanz C, Pozo F, Casas I, Garcia-Cenoz M, et al. Effectiveness of influenza vaccine against laboratory-confirmed influenza, in the late 2011--2012 season in Spain, among population targeted for vaccination. BMC Infect Dis. 2013;13(1):441.

22. Jimenez-Jorge S, de Mateo S, Delgado-Sanz C, Pozo F, Casas I, Pérez-Sautu U, et al. Estimating the 2012/13 influenza vaccine effectiveness using the cycEVA study, the Spanish component of the multicentre I-MOVE study. European Scientific Conference on Applied Infectious Disease Epidemiology (ESCAIDE), 5-7 November 2013, Stockholm, Sweden. ESCAIDE reference number 20131703. Abstract available from: http:// ecdc.europa.eu/en/ESCAIDE/past-ESCAIDE/Documents/ ESCAIDE-2013-abstract-book.pdf

23. Martínez-Baz I, Reina G, Martínez-Artola V, Fernández-Alonso M, Salcedo E, Mazón A, et al. [Effect of the time between symptom onset, swabbing and testing on the detection of influenza virus]. Enferm Infecc Microbiol Clin. 2012;30(1):11-4. Spanish. PMID:21903301

24. Armitage P, Berry G, Matthews JNS. Statistical methods in medical research. Malden, MA: Blackwell Science Ltd: 2002.

25. World Health Organization (WHO). Recommended composition of influenza virus vaccines for use in the 2012-2013 northern hemisphere influenza season. Geneva: WHO; Feb 2012. Available from: http://www.who.int/influenza/vaccines/virus/ recommendations/201202_recommendation.pdf

26. Kissling E, Valenciano M, Cohen JM, Oroszi B, Barret AS, Rizzo C, et al. I-MOVE multi-centre case control study 201011: overall and stratified estimates of influenza vaccine effectiveness in Europe. PLoS ONE. 2011;6(11):e27622. Available from: http://dx.doi.org/10.1371/journal. pone.0027622 PMID:22110695

27. Kavanagh K, Robertson C, McMenamin J. Estimates of influenza vaccine effectiveness in primary care in Scotland vary with clinical or laboratory endpoint and method--experience across the 2010/11 season. Vaccine. 2013;31(41):4556-63.

28. Martínez-Baz I, Martínez-Artola V, Reina G, Guevara M, Cenoz MG, Morán J, et al. Effectiveness of the trivalent influenza vaccine in Navarre, Spain, 2010-2011: a population-based testnegative case-control study. BMC Public Health. 2013;13(1):191. Available from: http://dx.doi.org/10.1186/1471-2458-13-191 PMID:23496887

29. Castilla J, Martínez-Baz I, Martínez-Artola V, Reina G, Pozo F, García Cenoz M, et al. Decline in influenza vaccine effectiveness with time after vaccination, Navarre, Spain, season 2011/12. Euro Surveill. 2013;18(5):20388. PMID:23399423

30. Kissling E, Valenciano M, Larrauri A, Oroszi B, Cohen JM, Nunes $B$, et al. Low and decreasing vaccine effectiveness against influenza $\mathrm{A}\left(\mathrm{H}_{3}\right)$ in 2011/12 among vaccination target groups in Europe: results from the I-MOVE multicentre casecontrol study. Euro Surveill. 2013;18(5):20390. PMID:23399425

31. Savulescu C, Jiménez-Jorge S, Delgado-Sanz C, de Mateo $\mathrm{S}$, Pozo F, Casas I, et al. Higher vaccine effectiveness in seasons with predominant circulation of seasonal influenza $A\left(\mathrm{H}_{1} \mathrm{~N}_{1}\right)$ than in $A\left(\mathrm{H}_{3} \mathrm{~N}_{2}\right)$ seasons: test-negative case control studies using surveillance data, Spain, 2003-2011. Vaccine. 2014;32(35):4404-11. Available from: http://dx.doi. org/10.1016/j.vaccine.2014.06.063 PMID:24968153

32. Kissling E, Valenciano M, Buchholz U, Larrauri A, Cohen JM, Nunes B, et al. Influenza vaccine effectiveness estimates in Europe in a season with three influenza type/subtypes circulating: the I-MOVE multicentre case-control study, influenza season 2012/13. Euro Surveill. 2014;19(6):20701. 
33. Skowronski DM, Masaro C, Kwindt TL, Mak A, Petric M, Li Y, et al. Estimating vaccine effectiveness against laboratoryconfirmed influenza using a sentinel physician network: results from the $2005-2006$ season of dual $A$ and $B$ vaccine mismatch in Canada. Vaccine. 2007;25(15):2842-51. Available from: http://dx.doi.org/10.1016/j.vaccine.2006.10.002 PMID:17081662

34. McMenamin J, Andrews N, Robertson C, Fleming D, Durnall H, von von Wissmann B, et al. Effectiveness of seasonal 2012/13 vaccine in preventing laboratory-confirmed influenza infection in primary care in the United Kingdom: mid-season analysis 2012/13. Euro Surveill. 2013;18(5):20393.

35. Pebody R, Andrews N, McMenamin J, Durnall H, Ellis J, Thompson $\mathrm{Cl}$, et al. Vaccine effectiveness of 2011/12 trivalent seasonal influenza vaccine in preventing laboratoryconfirmed influenza in primary care in the United Kingdom: evidence of waning intra-seasonal protection. Euro Surveill. 2013;18(5):20389. PMID:23399424

36. Irving SA, Donahue JG, Shay DK, Ellis-Coyle TL, Belongia EA. Evaluation of self-reported and registry-based influenza vaccination status in a Wisconsin cohort. Vaccine. 2009;27(47):6546-9. Available from: http://dx.doi. org/10.1016/j.vaccine.2009.08.050 PMID:19729083

37. Martinez-Baz I, Guevara M, Elia F, Ezpeleta C, Fernandez AM, Castilla J. [Influence of distinct criteria for selecting patients for swabbing on estimation of the effectiveness of the influenza vaccine]. Gac Sanit. 2014;28(3):225-9. Spanish. 10.1016/j.gaceta.2013.09.007

38. Valenciano M, Kissling E, Cohen JM, Oroszi B, Barret AS, Rizzo $C$, et al. Estimates of pandemic influenza vaccine effectiveness in Europe, 2009-2010: results of Influenza Monitoring Vaccine Effectiveness in Europe (I-MOVE) multicentre case-control study. PLoS Med. 2011;8(1):e1000388. Available from: http:// dx.doi.org/10.1371/journal.pmed.1000388 PMID:21379316

39. Fielding JE, Grant KA, Papadakis G, Kelly HA. Estimation of type- and subtype-specific influenza vaccine effectiveness in Victoria, Australia using a test negative case control method, 2007-2008. BMC Infect Dis. 2011;11(1):170. Available from: http://dx.doi.org/10.1186/1471-2334-11-170 PMID:21669006

40. European Centre for Disease Control and Prevention (ECDC). WHO Recommendation on influenza virus vaccines for the Northern Hemisphere 2013-2014 season. Stockholm: ECDC; 15 Mar 2013. Available from: http://www.ecdc.europa.eu/ en/activities/sciadvice/_layouts/forms/Review_DispForm. aspx?ID =737\&List=a3216f4c-fo40-4f $51-9 f 77-a 96046 \mathrm{dbfd} 72$

41. Valenciano M, Ciancio B, Moren A; Influenza Vaccine Effectiveness Working Group. First steps in the design of a system to monitor vaccine effectiveness during seasonal and pandemic influenza in EU/EEA Member States. Euro Surveill. 2008;13(43):19015. PMID:18947520 